\title{
A IMPORTÂNCIA DAS ABELHAS, DA SUSTENTABILIDADE E DOS CORREDORES ECOLÓGICOS: ESTRATÉGIAS DE ENSINO PARA OS ANOS INICIAIS DO ENSINO FUNDAMENTAL
}

\author{
MAIRA DOS SANTOS SILVEIRA ${ }^{1}$ \\ LAURA OESTREICH ${ }^{2}$ \\ EDUARDA TAIS BREUNIG ${ }^{3}$ \\ ANDRÉA INÊS GOLDSCHMIDT ${ }^{4}$
}

THE IMPORTANCE OF BEES, SUSTAINABILITY AND ECOLOGICAL CORRIDORS: TEACHING STRATEGIES FOR THE EARLY YEARS OF ELEMENTARY SCHOOL

\begin{abstract}
RESUMO
Cada vez mais se faz necessário discutir temas relacionados às questões ambientais, e nesse sentido a manutenção da biodiversidade e a importância das abelhas consistem em temas emergentes. A pesquisa objetivou investigar as percepções de estudantes de quintos anos sobre a importância das abelhas, da sustentabilidade e dos corredores ecológicos para a partir destas propor estratégias de conscientização. A pesquisa do tipo quanti-qualitativa, baseou-se num estudo de caso, desenvolvida com 45 estudantes de quintos anos do ensino fundamental em uma escola pública. Foi aplicado um questionário semiestruturado sobre concepções prévias acerca do tema, e posteriormente a sequência didática. Os dados foram tabulados conforme a análise de conteúdo de Bardin. Os resultados demonstram que os participantes apresentaram um maior conhecimento relacionado à sustentabilidade e às abelhas, se comparado aos corredores ecológicos. Contudo, por meio das atividades propostas, houve uma ampliação dos conhecimentos iniciais, corroborando para o processo de alfabetização científica.
\end{abstract}

Palavras-chave: Sustentabilidade. Concepções prévias. Alfabetização científica.

\section{ABSTRACT}

It is increasingly necessary to discuss topics related to the environment issues, and in this sense the maintenance of biodiversity and the importance of bees are emerging themes. The research aimed to investigate the perceptions of students of the fifth grade about the importancy of bees, sustainability and ecological corridors, to propose awaraness strategies based on these. The quanti-qualitative research was based on a case study, developed with 45 students of the fifth grade of elementary school in a public school. A semi-structured questionnaire was applied about previous concepts about the theme, and later on the didactic sequence. The data was tabuled accordingly to Bardin's content analysis. The results demonstrate that the participants presented a greater knowledge related to sustainability and bees, when compared to ecological corridors. However, through the proposed activities, there was an expansion of initial knowledge, corroborating the process of scientific literacy.

Keywords: Sustainability. Previous conceptions. Scientific literacy.

\footnotetext{
1 Graduada em Ciências Biológicas Licenciatura (Universidade Federal de Santa Maria). Mestranda em Educação em Ciências: Química da Vida e Saúde (Universidade Federal de Santa Maria).E-mail: mairasantossilveira@gmail.com. Orcid: orcid.org/0000-0001-5118-889X

2 Mestra em Educação em Ciências: Química da Vida e Saúde (Universidade Federal de Santa Maria) . Doutoranda em Educação em Ciências: Química da Vida e Saúde (Universidade Federal de Santa Maria). E-mail: lauraoestreich@hotmail.com. Orcid: orcid.org/0000-0001-5684-1149 3 Mestra em Educação em Ciências: Química da Vida e Saúde (Universidade Federal de Santa Maria). Secretaria Estadual de Educação RS. E-mail: dudabreunig@hotmail.com. Orcid: orcid.org/0000-0002-6249-3790

4 Doutora em Educação em Ciências: Química da Vida e Saúde (Universidade Federal de Santa Maria). Professora Adjunta do Departamento de Zootecnia e Ciências Biológicas na Universidade Federal de Santa Maria. E-mail: andreainesgold@gmail.com. Orcid: orcid.org/0000-0001-8263-7539
} 


\section{RESUMEN}

Cada vez és más necesario discutir temas relacionados con problemas ambientales, y en este sentido el mantenimiento de la biodiversidad y la importancia de las abejas son temas emergentes. La investigación tuvo como objetivo investigar las percepciones de los estudiantes de quinto año sobre la importancia de las abejas, la sostenibilidad y los corredores ecológicos, para proponer estrategias de concienciación basadas en estos. La investigación cuanti-cualitativa se basó en un estudio de caso, desarrollado con 45 estudiantes del quinto año en una escuela pública. Se aplicó un cuestionario semiestructurado sobre concepciones previas sobre el tema, y posteriormente sobre la secuencia didáctica. Los datos se tabularon según el análisis de contenido de Bardin. Los resultados demuestran que los participantes presentaron un mayor conocimiento relacionado con la sostenibilidad y las abejas, en comparación con los corredores ecológicos. Sin embargo, a través de las actividades propuestas, hubo una expansión del conocimiento inicial, corroborando con el proceso de alfabetización científica.

Palabras-clave: Sostenibilidad. Concepciones previas. Alfabetización científica.

\section{INTRODUÇÃO}

Cada vez mais, têm-se observado uma exploração indiscriminada dos recursos naturais, o que evidencia uma falta de preocupação com o equilíbrio ambiental do planeta. Dados do Fundo Mundial para a Natureza (WWF) (2019), alertam para a superexploração destes recursos, criando um descompasso ecológico, isto é, quando se utilizam os recursos em velocidade superior à sua capacidade de regeneração natural. Caso ações não sejam tomadas, o planeta possivelmente entrará em colapso devido ao continuo déficit ecológico. 0 cenário atual tem nos instigado a refletir e discutir aspectos que envolvam as questões econômicas, sociais, culturais e educacionais com uma percepção do uso consciente dos recursos naturais.

Em vista disso, um tema que vem sendo discutido com maior ênfase nos últimos anos é o acelerado processo de desaparecimento das abelhas, o qual pode estar ocorrendo por diversos fatores, entre eles a poluição, o desmatamento, a utilização de agrotóxicos, entre outros (LOPES et al., 2005).

Segundo Kerr (1987) as abelhas possuem grande importância para o ecossistema, pois são agentes polinizadores de plantas florais e tropicais, produtores de mel e geoprópolis assegurando a produção de frutos e sementes, além de manter a sobrevivência da fauna e da flora (KERR, 1987). Ricktts et al. (2008) constatam que, a polinização é essencial para a produção de alimentos, das quais as flores são polinizadas fornecendo frutos de boa qualidade, peso e sementes em maior quantidade.

Também o desmatamento culmina em uma fragmentação de hábitat, e este traz consequências para a sobrevivência das abelhas, uma vez que a mata é o hábitat de muitas espécies de abelhas, e as mesmas necessitam de locais específicos nela para sobreviver. Diante dessa problemática, uma estratégia sustentável que pode vir a ser utilizada são os corredores ecológicos, os quais são utilizados desde a década de 1970 para a conservação de ecossistemas fragmentados (DIAMOND, 1975; WILSON; WILLIS, 1975; MEFFE; CARROLL, 1997). Os corredores ecológicos atuam como conectores de áreas naturais isoladas entre elas, unidades de conservação, possibilitando o deslocamento de animais, dispersão de sementes e aumento da cobertura vegetal. Esses ainda formam uma rede de habitats, proporcionando uma conexão genética e aumento da diversidade, pois populações de fragmentos isolados tendem a ter uma menor probabilidade de sobrevivência (SODHI et al.,1999). 
As abelhas, a sustentabilidade e os corredores ecológicos consistem em temas relevantes para se discutir em sala de aula, proporcionando assim, um ensino voltado às reflexões relacionadas a alfabetização cientifica. De acordo com Chassot (2003) a ciência é uma linguagem e 0 indivíduo que é alfabetizado cientificamente tem a capacidade de ler essa linguagem. Linguagem esta que a natureza está escrita, assim, um analfabeto científico é aquele que é incapaz de fazer uma leitura do universo. 0 mesmo autor ainda discorre que a alfabetização científica deve ser iniciada nos primeiros anos do ensino fundamental e postergada para o ensino médio e demais níveis de ensino, uma vez que este é um processo complexo e que ocorre durante a vida toda.

0 professor, assim, deve empregar estratégias e recursos didáticos, envolvendo ações de ensino, aprendizagem e pesquisa que oportunizem a construção destes conhecimentos, estimulando reflexões e discussões sobre maneiras de realizar atividades sustentáveis no cotidiano. Para tanto, e diante da relevância desse tema, entendemos que conhecer as concepções prévias dos alunos acerca das abelhas, da sustentabilidade e dos corredores ecológicos é de suma importância, tanto para que possamos compreender quais são os valores que as crianças atribuem ao meio ambiente, quanto para que consigamos discutir como as ações antrópicas refletem no mesmo e para que possamos provocar mudanças na sociedade e em nós mesmos.

Ademais, investigar estas concepções consiste em uma ferramenta importante no processo de ensino e aprendizagem. Sobre isso, Ausubel (2003) explica que as concepções prévias, geradas a partir das vivências dos alunos, mesmo que sejam ideias espontâneas e por vezes equivocadas, são fundamentais para o processo de desenvolvimento cognitivo e atribuição de significados aos conhecimentos. É por meio da interação entre novos e antigos saberes que ocorre uma mudança do estado inicial dos conhecimentos prévios e, assim, uma aprendizagem significativa.

Diante do exposto, o presente trabalho teve por objetivo investigar e analisar as concepções de estudantes do quinto ano do ensino fundamental sobre a importância das abelhas, da sustentabilidade e dos corredores ecológicos, e a partir dessas propor estratégias potenciais a fim de sensibilizar os discentes para atitudes e práticas sustentáveis, contribuindo para uma alfabetização científica e a possibilidade de mudança e/ou ampliação dos conhecimentos prévios sobre a temática.

\section{TRAJETÓRIA METODOLÓGICA}

A pesquisa do tipo quanti-qualitativa, baseou-se num estudo de caso, desenvolvido a partir de um questionário semiestruturado sobre concepções prévias referente a importância das abelhas, da sustentabilidade e dos corredores ecológicos. A pesquisa de estudo de caso consiste na investigação profunda e exaustiva de um ou poucos objetos, de maneira que permita seu amplo e detalhado conhecimento (GIL, 2008).

A investigação foi realizada com duas turmas do quinto ano dos anos iniciais do Ensino Fundamental, totalizando 45 estudantes, de uma escola pública do município de Palmeira das Missões, RS. A atividade foi realizada durante os meses de setembro e outubro de 2020, durante as aulas de Ciências pelas pesquisadoras. Os alunos foram convidados a participarem da pesquisa, assinando juntamente aos familiares um termo livre e esclarecido. A pesquisa também contou com a participação das duas professoras regentes das turmas as quais colaboraram com o desenvolvimento das atividades. Para melhor elucidar optamos em dividir a pesquisa em três etapas, descritas a seguir: 


\section{Etapa investigativa inicial: as concepções prévias}

A pesquisa empírica consistiu na elaboração e aplicação de um questionário semiestruturado a fim de investigar as concepções prévias dos participantes referentes à temática abelhas, sustentabilidade e corredores ecológicos, sendo aplicado 0 questionário individualmente e realizado a leitura do mesmo para os alunos. As questões envolveram os conhecimentos gerais acerca da palavra sustentabilidade, palavras associadas ou não à sustentabilidade e conhecimentos sobre as abelhas (importância, riscos em relação ao seu desaparecimento), bem como conceito de corredores ecológicos e práticas necessárias para a manutenção da biodiversidade destes insetos. Em algumas questões os alunos podiam marcar mais de uma alternativa, podendo os resultados ultrapassar a frequência de $100 \%$.

Os dados foram tabulados e analisados de acordo com a Análise de Conteúdo (BARDIN, 2011), pois, por meio desta, torna-se possível descrever, analisar e interpretar as ideias expressas nas respostas fornecidas pelos estudantes. De acordo com esta autora, a categorização é uma operação de classificação de elementos constitutivos de um conjunto, por diferenciação e, seguidamente, por reagrupamento segundo o gênero (analogia).

Os resultados tabulados serviram de indicadores para a preparação das atividades de ensino, de modo que pudessem partir das concepções iniciais dos próprios alunos, e construírem os novos conhecimentos a partir destes.

\section{Etapa Sensibilizadora: elaboração e desenvolvimento de estratégias de ensino}

As estratégias de ensino elaboradas, contaram com 0 apoio das professoras responsáveis pelas turmas participantes, sendo desenvolvidas em quatro tardes distintas, totalizando 23 horas/aula em cada uma das turmas. Desta forma, previamente, foram discutidos os resultados encontrados na etapa anterior (percepções dos estudantes) com as docentes, e, em ação conjunta, elaboramos e selecionamos as atividades que foram realizadas em cada uma das turmas.

Estas visaram: sensibilizar para as temáticas importância das abelhas, da sustentabilidade e dos corredores ecológicos; oportunizar mudanças conceituais; e ainda, ampliar os conhecimentos iniciais e/ou desmistificar possíveis fragilidades e conceitos reducionistas sobre as temáticas, previamente identificadas na investigação inicial. As atividades contaram com: Estratégia de ensino 1 Conversa introdutória (3 horas-aula); Estratégia de ensino 2 - Conhecendo as abelhas (5 horas-aula); Estratégia de ensino 3 - Práticas sustentáveis: Confecção de modelo didático e plantio de espécies melíferas (5 horas-aula); e Estratégia de ensino 4 - Organização e divulgação científica sobre a importância das abelhas e a manutenção delas através de corredores ecológicos (10 horas-aula).

As estratégias de ensino serão melhores apresentadas no item resultados e discussão.

\section{Etapa Avaliativa: validação das estratégias de ensino}

Para avaliação das atividades foi solicitado aos alunos uma ilustração a partir da afirmação: "Desenhe 0 que você aprendeu sobre as atividades desenvolvidas". Os desenhos foram recolhidos e analisados pelas pesquisadoras. A metodologia aplicada para analisar os desenhos, a exemplo de 
outros estudos, baseia-se em uma interpretação simples identificando a presença de elementos que designam como o sujeito percebe o meio ambiente ao seu redor (BOER, 1994).

Almeida (2003) argumenta que, para os alunos, os desenhos e escrita são maneiras de demostrar coisas, sendo estas um modo de expressar algo, representando a realidade dos elementos que observam e com isso ampliando seu domínio sobre 0 ambiente.

\section{RESULTADOS E DISCUSSÃO}

\section{Etapa investigativa inicial: as concepções prévias}

Os estudantes foram questionados sobre o significado de sustentabilidade sendo constatado que $22,2 \%$ nunca havia ouvido a respeito do termo. Os que o reconheceram, 0 associaram a tornar o meio ambiente um local sustentável ou agradável para viver (31,1\%), sustentação física do corpo associada ao ato da alimentação e manutenção do corpo (29,0\%), a ação verbal em si, 0 ato de fazer ou construir algo, inclusive moradia (17,7\%).

Tais resultados evidenciam que para uma amostra significativa dos alunos a sustentabilidade é tornar o meio ambiente sustentável por meio da preservação, equilíbrio do meio ambiente, manutenção de plantas e animais, assim como reduzir e reciclar. Segundo Guisso e Baiôco (2000) deve-se assumir de maneira consciente as condições de existência a fim de exercitar a idoneidade para decidir os melhores caminhos para o desenvolvimento sustentável do mundo, com aprendizados que possibilitem refletir criticamente sobre o cotidiano em favor do meio ambiente, uma vez que a ação do homem é fator crucial na promoção da sustentabilidade.

Na concepção prévia dos alunos em relação à sustentabilidade, evidenciamos também o sentido de sustento do corpo humano, sem menção do real significado da palavra. Segundo a Língua Portuguesa, dicionário Michaelis (2020), o termo sustentar provém de amparar; dar ou receber alimentos; condições materiais ou cuidados fundamentais à manutenção da vida; garantir alimentação a quem realiza trabalho pesado. As respostas dos alunos estão de acordo com o entendimento social de seu cotidiano, dando sentido à vida individual ou em conjunto, podendo gerar uma problemática em relação à conceituação de sustentabilidade, pois a palavra sustentar pode ser erroneamente confundida com as necessidades de satisfações dos indivíduos como compras de alimentos, roupas, objetos e, até mesmo, na caça de outras espécies, demostrando que possíveis hábitos de consumo contradizem o conceito sustentável necessário para a preservação do planeta.

Os alunos ainda afirmaram não saber responder tal questionamento (22,2\%). Souza (2015) descreve que aproximar os conteúdos de ciências ao contexto social viabiliza ao discente encontrar sentindo no que estuda e o prepara para a diversidade da vida. Lorenzetti e Delizoicov (2001) propõem uma alfabetização científica em ensino de ciências que não enfatizem apenas a formação de futuros cientistas, mas que seja capaz de fornecer subsídios para que os alunos compreendam e discutam os significados dos assuntos científicos e os apliquem em seu entendimento de mundo. Logo, é importante que os alunos compreendam a sustentabilidade e possam aplicá-la nas suas ações diárias, favorecendo ações para a preservação do planeta.

Quando oferecido aos alunos palavras que eles pudessem marcar como associadas ou não à sustentabilidade, evidenciamos os seguintes resultados, apresentados na Tabela 1. 
Tabela 1 - Frequência das respostas dos alunos de anos iniciais à identificação de palavras associadas à sustentabilidade como sendo verdadeiras ou falsas.

\begin{tabular}{lcc}
\hline \multicolumn{1}{c}{ Palavras atribuídas } & Palavras associadas como verdadeiras & Palavras associadas como falsas \\
\hline Meio ambiente & 91,1 & 8,9 \\
Cuidados com meio ambiente & 91,1 & 8,9 \\
\hline Reciclagem & 86,7 & 13,3 \\
Captação de água da chuva & 82,2 & 18,8 \\
Coleta seletiva & 82,2 & 18,8 \\
Preservação & 80,0 & 20,0 \\
Plantio de florestas & 77,8 & 22,2 \\
Apagar a luz & 68,9 & 32,1 \\
Composteira & 22,2 & 78,8 \\
Morte de abelhas & 20,0 & 80,0 \\
Destruição ambiental & 20,0 & 80,0 \\
Poluição & 20,0 & 80,0 \\
Desmatamento & 17,8 & 83,2 \\
Pobreza & 13,3 & 87,7 \\
\hline Agrotóxicos & 8,9 & 91,1 \\
\hline
\end{tabular}

Fonte: elaborada pelas autoras.

Tais dados evidenciam que os alunos possuem maior percepção em relação à identificação de palavras associadas à sustentabilidade, pois apontam meio ambiente (91,1\%), reciclagem (86,7\%), coleta seletiva $(82,2 \%)$ e preservação (80\%), demonstrando que 0 conceito de sustentabilidade está atrelado às questões ambientais (MELO; BRENNAND, 2004).

Esse conhecimento deve ser percebido pelo educador, pois há temáticas ainda pouco exploradas como a reciclagem, por exemplo. De acordo com Caron (2011) apesar da temática ser muito comentada, é pouco trabalhada, afinal o problema do lixo não acaba quando o colocamos para fora de casa, é neste momento que ele começa e que muitas cidades não possuem lugares adequados como aterros sanitários, onde o lixo é depositado adequadamente para evitar uma possível proliferação de animais transmissores de doenças.

De acordo com o trabalho desenvolvido por Godoy et al. (2008) os alunos são capazes de identificar os principais problemas ambientais, mas não de forma mais ampla com apropriação do conteúdo. Os alunos inferiram que as palavras: agrotóxicos (91,1\%), pobreza (87,7\%), desmatamento (80\%), destruição ambiental (80\%) e morte das abelhas (80\%) não estão associadas à sustentabilidade, porém estes aspectos estão relacionados às questões de intervenção do homem no meio ambiente.

Silva et al. (2014) argumentam que o simples fato de alguém existir gera algum tipo de impacto ambiental e social, a sustentabilidade não tem foco individual, mas sim coletivo. Deve-se considerar todo o conjunto complexo onde o homem está inserido, abandonando uma consciência individualista, em busca de uma coletiva. Em contrapartida, Guimarães (1995) salienta que o homem é analisado através de seu comportamento incorreto em relação à natureza, diante disso, o educador deve tomar 0 cuidado de não desenvolver no aluno à visão do homem como o centro, "o ser superior", que domina e se apropria da natureza, proporcionando o desenvolvimento da preservação do meio ambiente 
através da exclusão do homem, pois o antropocentrismo pode ser obstáculo epistemológico para a compreensão da dinâmica ecológica da natureza.

A mortalidade das abelhas foi inserida como uma das temáticas por se tratar de uma problemática atual e que se apresentava como objeto de estudo neste trabalho. A biodiversidade tem sido afetada devido às ações antrópicas, ocasionando o desaparecimento das abelhas como consequência da poluição, desmatamento, utilização de agrotóxicos, entre outras ações. Maia (2004) inclusive argumenta que a destruição de árvores, por exemplo, elimina a possibilidade de as abelhas conseguirem sobrevier em locais específicos dos quais precisam para poder armazenar o mel. 0 empobrecimento da vegetação natural elimina as espécies de abelhas e, assim, diminui também a floração em cada época do ano.

Em continuidade à investigação inicial, os alunos foram questionados acerca da importância das abelhas, se sabiam que estas estavam morrendo em maior número nos últimos anos e se reconheciam prejuízos caso houvesse 0 desaparecimento destes insetos no planeta. Todas estas questões eram abertas e os resultados para essas compõem a Tabela 2.

Tabela 2 - Frequência das respostas dos alunos de anos iniciais acerca da importância das abelhas e os prejuízos em função de seu desaparecimento no planeta.

\begin{tabular}{|c|c|c|c|}
\hline Importância & Percentual & Prejuízos & Percentual \\
\hline Polinização & 33,3 & Não teria mel & 43,5 \\
\hline Produção do mel & 33,3 & Não teria Polinização & 13,0 \\
\hline $\begin{array}{l}\text { Reprodução da flora/ Importante para as flores/ } \\
\text { Crescimento das plantas/ }\end{array}$ & 13,2 & $\begin{array}{l}\text { Não existiria flores e frutos/ As flores não iriam } \\
\text { florescer/ As plantas murchariam/ }\end{array}$ & 10,8 \\
\hline $\begin{array}{l}\text { Produzir mel e ajudar na polinização para as } \\
\text { plantas crescerem }\end{array}$ & 6,7 & $\begin{array}{l}\text { Não existiria vida/ Um desequilíbrio ambiental em } \\
\text { que a maioria dos seres vivos morreriam/ Seria } 0 \\
\text { fim das abelhas }\end{array}$ & 17,4 \\
\hline $\begin{array}{l}\text { Sem a polinização, morte das plantas e das } \\
\text { pessoas }\end{array}$ & 6,7 & Não conseguiríamos respirar & 2,2 \\
\hline Não responderam & 6,7 & Não responderam & 13,00 \\
\hline Total & 100 & Total & 100 \\
\hline
\end{tabular}

Fonte: elaborada pelas autoras.

Quando indagados sobre as "abelhas estarem morrendo", 73,3\% dos participantes afirmaram estar cientes desta situação. Ultimamente, por meio de mídias sociais, televisão, jornal e outros meios de comunicação, cada vez mais está sendo abordado a importância das abelhas para toda a vida no planeta e como elas estão morrendo devido às consequências das ações humanas. Em vista disso salientamos que as abelhas apresentam um acelerado processo de desaparecimento, 0 qual pode estar ocorrendo por vários fatores (LOPES et al., 2005) e este pode ser um tema atrativo para trabalhar sobre sustentabilidade com as crianças.

Os resultados mostram, ainda, que os alunos elencam a importância da polinização das abelhas (33,3\%), sendo fundamental para o meio ambiente. De fato, a polinização é responsável por auxiliar na reprodução e na diversidade genética de $87,5 \%$ das espécies de plantas (FA0, 2018). Contudo ao citar a produção de mel $(43,5 \%)$ como principal fator de prejuízo ao meio ambiente, fica evidente a necessidade de um ensino de ciências voltado para a valorização dos insetos (abelhas), a fim de superar 
uma possível visão antropocêntrica. Este resultado vai ao encontro com os pressupostos de Abreu e Bussinguer (2013), os quais explicam que por meio de problemáticas ambientais é possível identificar a ampla visão antropocêntrica onde a natureza serve ao sujeito e a seus interesses econômicos.

Evidentemente 0 mel e o própolis são produtos apícolas conhecidos mundialmente dos quais as propriedades são utilizadas para fins nutricionais e terapêuticos. Estas utilidades vêm desde os tempos primordiais da humanidade (BARBOSA et al., 2009; FREITAS et al., 2004), porém não deveriam ser identificados como o maior prejuízo, já que são essenciais para a manutenção do ecossistema. Uma forma de mostrar a importância, a beleza e o valor dos ecossistemas é por meio de ações que proporcionem aprendizado, sendo uma alternativa 0 uso de trilhas ecológicas (SILVA, 2014). Nesta perspectiva, Subramaniam (2002) fomenta a necessidade de um aprendizado baseado na investigação científica em ambiente natural, utilizando de ferramentas como 0 uso de jardins, com 0 intuito de possibilitar um currículo que abranja um ensino não conteudista e fragmentado da ciência.

Outro ponto levantado pelos alunos é que não teria polinização (13\%) e não existiria flores e frutos (4,3\%). Em seus estudos Corby et al. (2016) salientam que não há possibilidade de um substituto para a polinização capaz de executar de forma tão eficaz e rápida o trabalho de uma abelha, sendo que 0 declínio destes insetos poderá prejudicar a nossa alimentação, uma vez que as frutas e os produtos agrícolas tenham baixa ascensão, isso causaria uma ameaça alimentar mundial.

Acerca deste questionamento podemos destacar a sensibilização dos alunos em relação a importância das abelhas para nosso planeta, pois 6,5\% compreendem que ocorrerá um desequilíbrio ambiental em que a maioria dos seres vivos morreria e não existiria vida (8,7\%).

Quando questionados os motivos pelos quais as abelhas estariam morrendo, o principal fator apontado foi o uso de agrotóxicos (40\%), o que de fato é evidente, pois a utilização destes inseticidas, herbicidas e/ou fungicidas afetam a sobrevivência dos polinizadores. Pettis et al. (2013) alegam que os inseticidas e herbicidas agem de forma indireta, reduzindo a presença de plantas fornecedoras de néctar e pólen; os fungicidas, embora percebidos como seguros para insetos, podem interromper 0 comportamento de alimentação das abelhas, de forma repelente, e sendo carreados para a colmeia junto com o néctar e pólen, assim afetando 0 desenvolvimento das larvas e prejudicando 0 sistema imunológico das abelhas.

Outras possíveis causas para 0 aumento da morte das abelhas salientadas pelos alunos são as queimadas e desmatamento (11,1\%) e poluição do meio ambiente (9\%) apontando que os impactos ambientais estão relacionados com as ações antrópicas. Estas ações prejudicam as abelhas que vivem em ocos de árvores, mais de 300 espécies vêm sendo prejudicadas com as derrubadas dessas árvores (KERR et al., 2001).

Os alunos ainda citam que as abelhas picam e perdem o ferrão (2,2\%). Essa concepção deve ser observada pelo educador, pois é fundamental 0 aluno aprender sobre as características dos insetos, neste caso sobre as abelhas, possibilitando 0 entendimento sobre a defesa deste animal. Salientamos que as abelhas são animais selvagens e algumas espécies atacam quando sentem necessidade de proteger sua integridade e/ou quando sua colmeia está ameaçada. Anjos (2020) diz em seus estudos que $86 \%$ dos alunos associam abelhas ao medo de ser picado, uma vez que estas concepções são exaltadas pelos noticiários criando um estereótipo nocivo a este inseto.

Posteriormente, os alunos foram indagados sobre as atitudes necessárias para diminuir a morte das abelhas tendo-se os seguintes resultados: combater 0 uso de agrotóxicos (42,2\%), parar de desmatar ou destruir $(22,2 \%)$, criar abelhas $(6,7 \%)$, parar de poluir ou acumular lixo $(6,6 \%)$, cuidar do meio ambiente $(4,4 \%)$ e as abelhas pararem de picar as pessoas (2,2\%). Ainda $11,1 \%$ não responderam. 
0 maior percentual esteve relacionado a não utilizar agrotóxicos, corroborando com os resultados anteriores. As ações antrópicas foram amplamente citadas pelos alunos, como: não desmatar (11,1\%), não matar, mas sim criar abelhas (11,1\%), humanos não matarem abelhas $(6,7 \%)$ e não poluir $(2,2 \%)$. Entre outros fatores de risco causados pelo homem, devemos considerar as queimadas e 0 corte em geral de árvores de porte médio e grande, sem deixá-las chegar a ficar ocas, eliminando as condições que muitas abelhas precisam para poder viver e armazenar mel (SOUZA et al., 2007).

Sem dúvida algumas práticas podem ser realizadas para minimizar a morte das abelhas, dentre elas: a conservação vegetativa nativa, sendo áreas circundantes as áreas agrícolas e urbanas, a fim de diminuir o impacto da redução da disponibilidade de néctar e de pólen (GARIBALDI et al., 2011); buscar evitar o uso de agrotóxicos no período de florescimento das culturas e, quando necessário, aplicar produtos seletivos aos polinizadores (ROSA et al., 2017).

Por fim os discentes foram questionados sobre corredores ecológicos e percebemos que apenas $4,4 \%$ dos alunos os associaram a lugares de preservação ambiental e 2,2\% associaram a animais polinizadores. Para 93,4\% dos participantes o termo é totalmente desconhecido. Este percentual expressa o pouco conhecimento voltado para a área da ecologia, apesar de as disciplinas centrais de Ciências Naturais serem voltadas para esta subárea.

Segundo Silva et al. (2014), muitos educadores têm em sua formação um contato breve com os conhecimentos específicos dessa área, em seus estudos, o pedagogo é considerado um professor polivalente por ensinar sete componentes curriculares nos anos iniciais do Ensino Fundamental. Contudo os conteúdos específicos de ecologia, que também devem ser trabalhados no ensino de ciências, em pedagogia não são abordados especificadamente e os professores, por não possuírem uma formação adequada, acabam baseando-se apenas por utilizar de recursos como livros didáticos e internet.

Diante disso, um aspecto a ser contextualizado é a utilização de espaços fora do âmbito escolar, a fim de auxiliar 0 docente no desenvolvimento do conteúdo e 0 discente a interligar as suas concepções nas ações realizadas a partir do conteúdo estudado. É fundamental sensibilizar os alunos sobre importância da conexão ambiental realizada pelos corredores ecológicos.

O Sistema Nacional de Unidade de Conservação define corredores ecológicos como:

Porções de ecossistemas naturais ou seminaturais, ligando unidades de conservação, que possibilitam entre elas o fluxo de genes e movimento da biota, facilitando a dispersão de espécies e a recolonização de áreas degradadas, bem como a manutenção de populações que demandam para sua sobrevivência áreas com extensão maior do que aquela das unidades individuais (SNUC, 2000, p. 16).

Essas unidades de conservação, quando interligadas, possibilitam a sobrevivência dos animais que as polinizam como as abelhas, pois a polinização é fundamental tanto para os ecossistemas (WRATTEN et al., 2012), quanto para a agricultura (RICKETTS et al., 2008).

A utilização de espécies melíferas em corredores ecológicos se mostra essencial para a manutenção dos ecossistemas, visto que é através da produção de néctar das flores que os polinizadores são atraídos, e estes, em busca de recursos alimentares, viabilizam a polinização das espécies, no qual é indispensável para que haja a formação de frutos e sementes.

Diante das reflexões do questionário inicial, foi possível, por meio da validação da dinâmica das estratégias, etapa sensibilizadora, perceber uma necessidade de diálogo sobre a temática. 


\section{Etapa Sensibilizadora: elaboração e desenvolvimento de estratégias de ensino}

Em relação as estratégias desenvolvidas algumas discussões são inferidas.

A Estratégia de Ensino 1: conversa introdutória, contou com a projeção de imagens e explanação sobre a temática, demonstrando concepções equivocadas e assertivas, cabendo às professoras-pesquisadoras ouvir, compreender e mobilizar o refletir deste aluno em relação a sua concepção e, desta maneira, mediar uma reflexão humanizada em relação ao mundo.

Segundo os pesquisadores canadenses, Godin e Gingras (2000), as palavras agregam valores referentes a um amplo conhecimento dos métodos utilizados para se produzir o conhecimento científico, noções dos conteúdos abordados pela ciência e ao estabelecimento de relações entre a ciência e a sociedade, juntos passam a fazer parte da cultura, modificando a forma como as pessoas percebem 0 mundo.

Em continuidade trabalhamos com os alunos em sala de aula, a História da Turma da Mônica: Sustentabilidade, de Mauricio de Sousa (2012). Nesta, os personagens do cartunista Maurício de Sousa ensinam as crianças e adolescentes a entender temas como sustentabilidade, reciclagem de lixo, aquecimento global e consumo consciente na revista em quadrinhos. Alves (2001) argumenta que a história em quadrinhos é uma ferramenta de comunicação de massas, cujas histórias são narradas através de imagens desenhadas e textos inter-relacionados, que possuem a capacidade de informar, entreter e contribuir para a formação da criança.

Posteriormente, a Estratégia de Ensino 2: conhecendo as abelhas foi voltada para visitação do Campus UFSM-Palmeira das Missões, onde existe um local de criação apícola. Nesse momento houve uma conversa e os alunos puderam visualizar as abelhas sem ferrão: Mirim emerina (Plebeia emerina), Jataí (Tetragonisca angustula) e Manduri (Melipona marginata). Além disso tiveram a oportunidade de realizarem questionamentos ao professor a fim de esclarecer suas dúvidas sobre as abelhas: "Todas as abelhas tem ferrão?"; "Como elas sabem o caminho de casa"; "Como elas se alimentam?"; "Como elas fazem o mel?"; "Lá na minha tia têm abelhas na parede do muro."; "Na Antártida têm abelhas?". Ainda puderam observar como é realizado a captura de abelhas e acompanhar a construção de uma armadilha, entender como é extraído o mel e experimentar o mel de abelha sem ferrão. Ao final da visitação foi solicitado aos alunos que trouxessem para a próxima aula materiais recicláveis para a confecção de um protótipo de corredor ecológico para abelhas (Figura 1). Desta forma podemos inferir a importância dos espaços não-formais diante da aprendizagem para os alunos. Pereira e Burity (2011) destacam que:

As atividades educativas fora do espaço formal da sala de aula são um recurso que pode ser utilizado para enriquecer os conhecimentos do conteúdo do ensino de Ciências. [...] associando o conteúdo ministrado em sala de aula com a realidade do meio e dos acontecimentos diários, proporcionando uma difusão de conhecimentos de maneira descontraída e momentos de socialização (PEREIRA; BURITY, 2011, p. 1). 
Figura 1 - Visitação ao campus UFSM/PM para conhecer o setor apícola e explanação da importância sobre abelhas: a e b) observação das caixas de abelhas sem ferrão; c) construção de armadilha para capturar abelhas; d) extração e experimentação do mel de abelha sem ferrão.

A

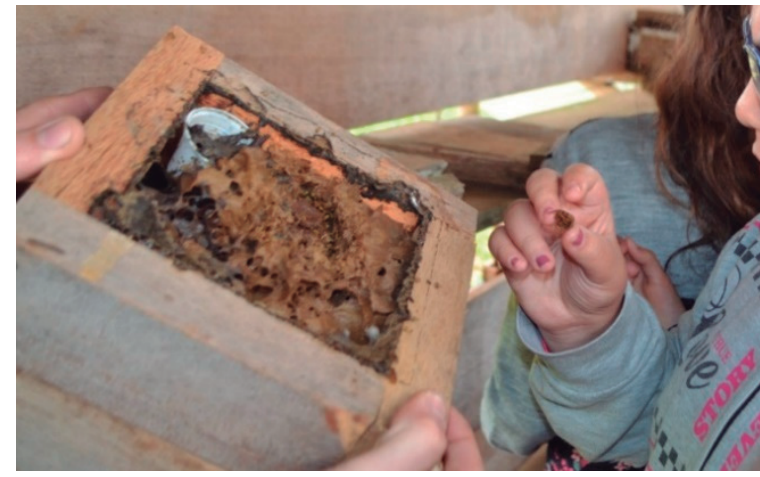

C

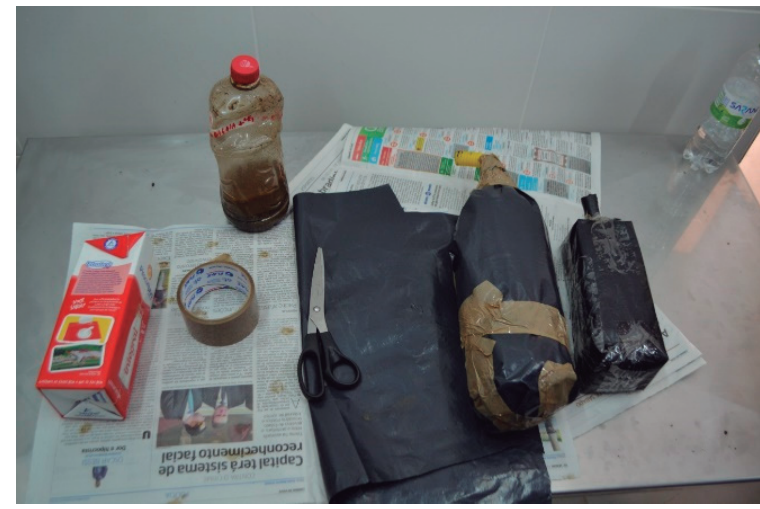

B

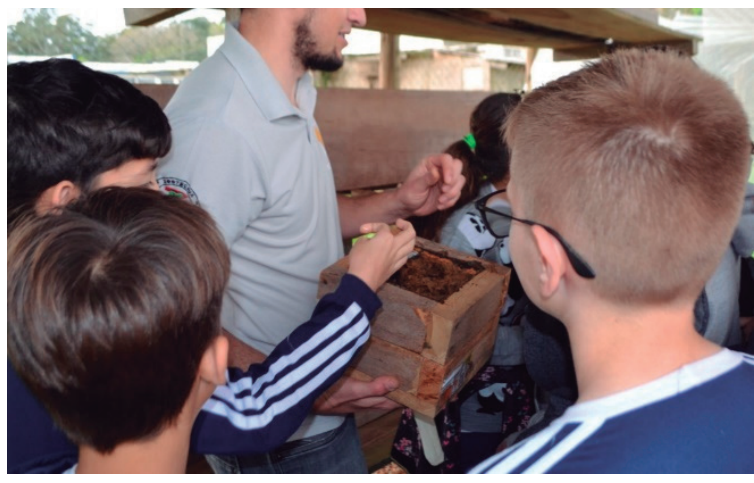

D

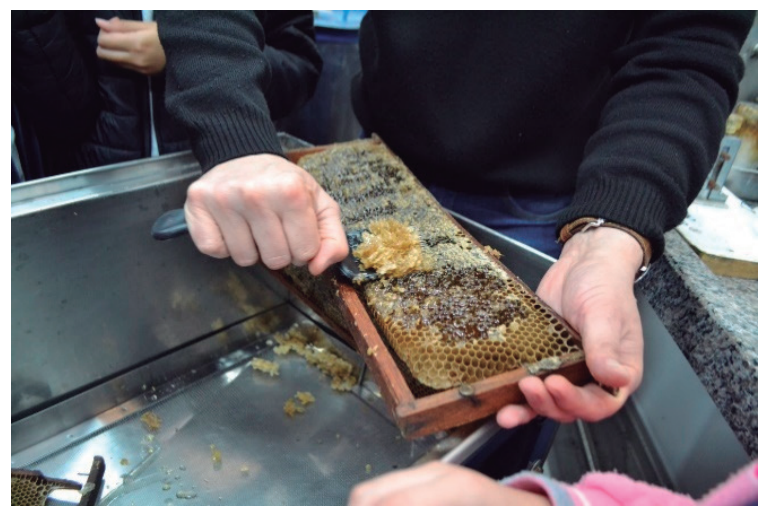

Fonte: acervo próprio.

Em relação à Estratégia de Ensino 3: Práticas Sustentáveis: confecção de modelos didáticos e plantio de espécies melíferas os alunos novamente se mostraram muito participativos. Neste momento foi solicitado aos alunos um círculo com suas classes onde estes pudessem conversar entre si, oportunizando a nós, como professoras-pesquisadoras, um contato mais próximo com os estudantes. A partir daí foram construídos modelos didáticos de colmeias e abelhas, com materiais solicitados em aula anterior, sendo estes: caixa de ovos, caixas de madeira (de verduras), garrafas pet, rolinho de papel higiênico, casca triturada de ovos para adubação, terra orgânica, plantas, fita isolante, corda de anzol, tinta amarela e preta, lona preta e cola quente. Durante este processo foi explicado a eles acerca da anatomia das abelhas, para que percebessem suas principais características no grupo dos insetos e também sobre sua importância ecológica. Igualmente foi discutido sobre corredores ecológicos e a importância destes para abelhas, com a utilização de plantas melíferas como estratégia para a conservação de ecossistema.

Posteriormente a construção dos modelos de abelhas e colmeias (Figura 2), foi desenvolvido com os alunos um protótipo de corredor ecológico para abelhas, sendo realizado o plantio de mudas melíferas (Figura 3). 0 plantio foi realizado pelos próprios alunos, no qual cada turma ficou responsável pelo plantio de quatro caixas de mudas melíferas juntamente com auxílio das pesquisadoras, dois colegas pesquisadores convidados e professoras responsáveis pelas turmas. Foram utilizadas quatro mudas melíferas, terra orgânica, cascas de ovos trituradas, água, caixas de madeiras e lona 
preta, sendo materiais solicitados pelas professoras em aula anterior. As mudas melíferas Alecrim (Rosmarinus officinalis), Lavanda (Lavandula officinalis), Manjericão (Ocimum basilicum) e Girassol (Helianthus annuus) foram plantadas em caixas de madeira, as quais estavam forradas com lona preta, onde foram adubadas com terra orgânica, cascas de ovos e regadas com água. Este material construído permaneceu na escola.

0 diálogo ocorreu durante todo o momento de montagem dos modelos didáticos. Souza (2007, p. 110) ressalta que "[...] é possível a utilização de vários materiais que possibilitem desenvolver 0 processo de ensino e de aprendizagem, isso faz com que facilite a relação professor - aluno - conhecimento". 0 mesmo autor ainda argumenta que de forma conjunta, professor e aluno, podem concluir sobre a importância do emprego de recursos didáticos nas aulas de ciências, a partir do momento em que 0 aluno consegue aprofundar, ampliar e produzir outros conhecimentos provenientes de uma estratégia inicial. Logo, cabe ao professor escolher o material mais adequado para fornecer um aprendizado efetivo e dinâmico (SOUZA, 2007).

Guimarães et al. (2006, p. 307) corroboram enfatizando a importância dos "modelos didáticos como construções teóricas que nos possibilitam uma aproximação mais sistemática do objeto de estudo e, dessa forma, da sua compreensão".

Figura 2 - Desenvolvimento da confecção de abelhas, com matérias recicláveis, para o corredor ecológico para abelhas: a) criação de modelo de abelhas e colmeias; b) modelo didático abelhas.

A
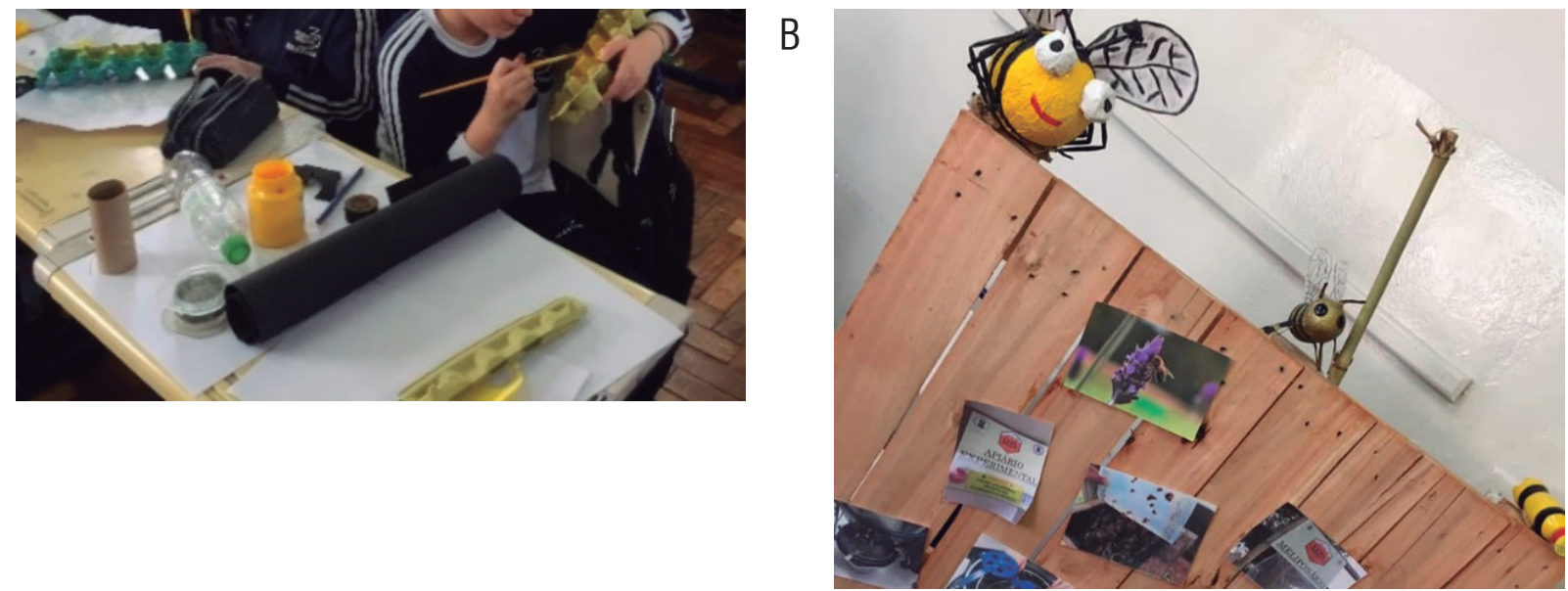

Fonte: acervo próprio. 
Figura 3 - Alunos de anos inicias desenvolvendo atividade de plantação de flores melíferas para o corredor ecológico para abelhas: a) alunos plantando as flores; b) protótipo de corredor ecológico para abelhas.
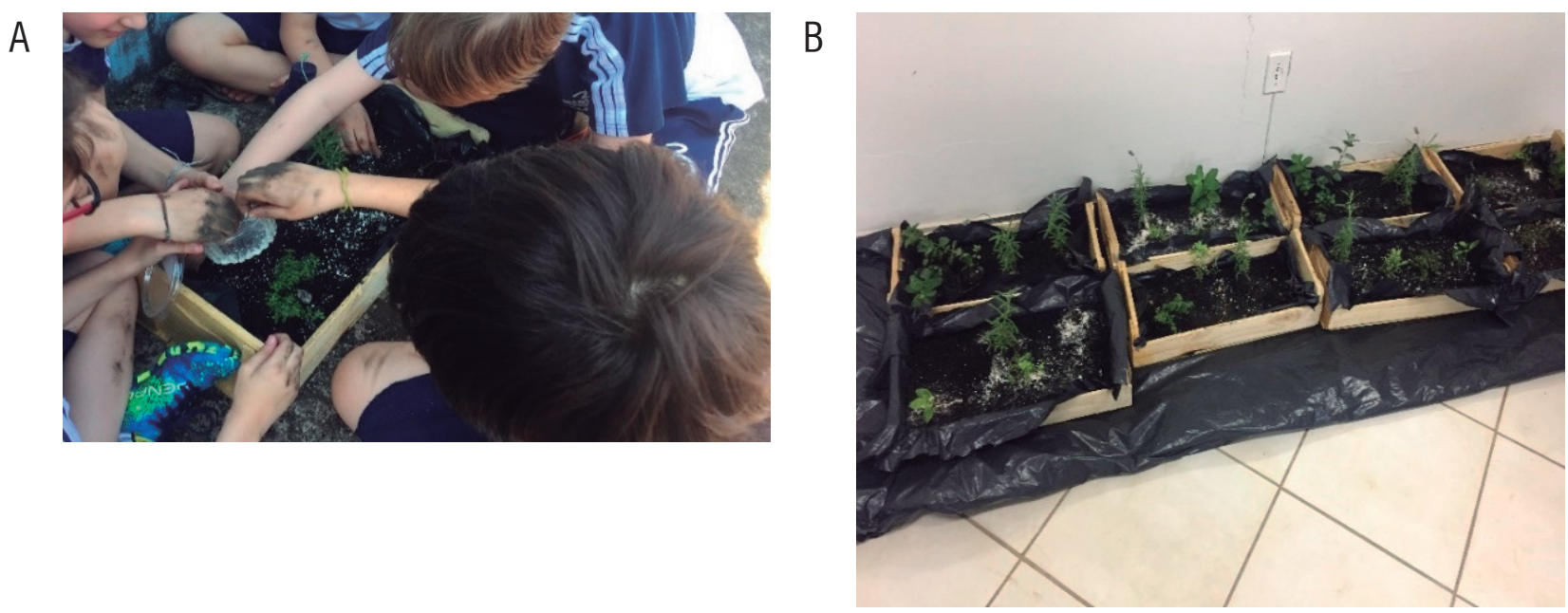

Fonte: acervo próprio.

A última etapa sensibilizadora, Estratégia de Ensino 4: Organização e divulgação científica sobre a importância das abelhas e a manutenção delas através de corredores ecológicos, deu-se na apresentação dos alunos na Feira escolar com a temática Sustentabilidade. Os educandos organizaram uma sequência de apresentação por bancada e durante a visitação de alunos de outros anos, professores, pais e amigos, os educandos tinham a possibilidade de abordar a temática, elaborada durante a intervenção das estratégias, explanando o conhecimento adquirido. Desta maneira foi possível observar como o conhecimento foi construído de modo significativo, pois a partir de suas apresentações, os alunos evidenciaram a confiança acerca da temática sem equívocos recorrentes, indagando falas como: "As abelhas são importantes para a manutenção da vida, pois realizam a polinização."; "É a partir da polinização que as abelhas ajudam a natureza a ter novas flores e frutos, e com isso, alimentos para os seres vivos."; "Você sabia que nem todas as abelhas tem ferrão? Uma delas se chama Jataí, são abelhas bem pequenas."; "É importante usar menos produtos químicos, eles são os agrotóxicos e prejudicam as abelhas e a natureza". As falas dos educandos evidenciam a importância da troca de ensino aprendizagem entre professor e aluno, Mortimer e Scott (2002) destacam a importância da participação dos estudantes nas atividades dialógicas, entre o professor e a classe, na produção de significados a partir da apropriação das suas próprias ideias.

Após o desenvolvimento das ações da etapa sensibilizadora, os alunos ilustraram o que haviam aprendido sobre as atividades, representando através de desenhos a importância da preservação do meio ambiente, a necessidade de não poluirmos e não desmatarmos, a importância do plantio de mudas de árvores e de plantas melíferas para a preservação das abelhas. Assim como outras práticas sustentáveis necessárias e que não foram associadas diretamente ao assunto em questão, mas que igualmente são importantes e interferem, como a coleta seletiva, o uso consciente da água e 0 uso de tecnologias limpas e fontes de energias renováveis, além de ouvirmos mais os cientistas (Figura 4). 
Diante destes resultados, os alunos demostram, de forma significativa, a aprendizagem acerca da temática desenvolvida nas estratégias de intervenção. Silva et al. (2018) salientam que 0 aluno evidencia suas preocupações ao falar sobre a necessidade de não pensar apenas em si, mas sim em todos que estão a sua volta. Podemos perceber que as ações desenhadas pelos alunos expressaram o cuidado para com o meio ambiente, de modo que, para que exista sustentabilidade, é necessário um equilíbrio entre sociedade e ambiente, possibilitando o uso dos recursos naturais de maneira a respeitar os limites da natureza (CAVALCANTI, 1998; JACOBI, 2003; JONES et al., 2010) e não meramente uma preservação contemplativa do meio ambiente.

Figura 4 - lustração dos alunos de anos inicias em relação as atividades realizadas após as etapas sensibilizadoras: a) desenho sobre o corredor ecológico; b) desenho sobre a polinização das flores.

A

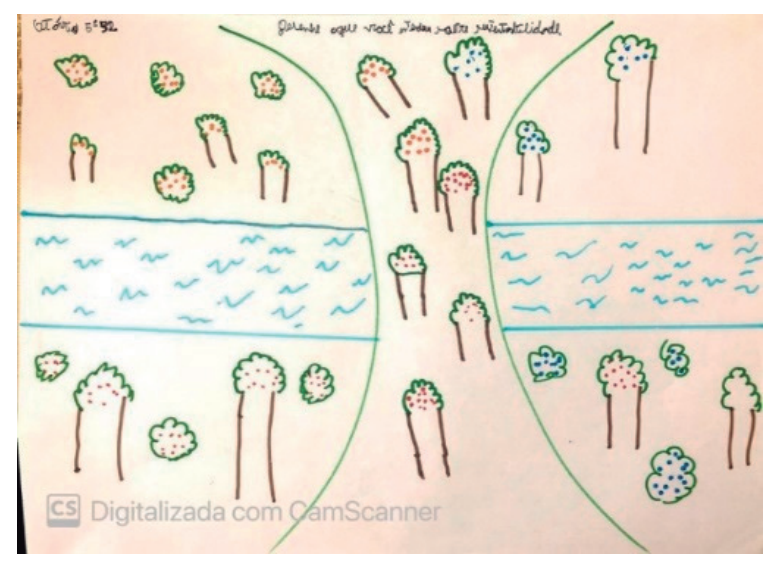

B

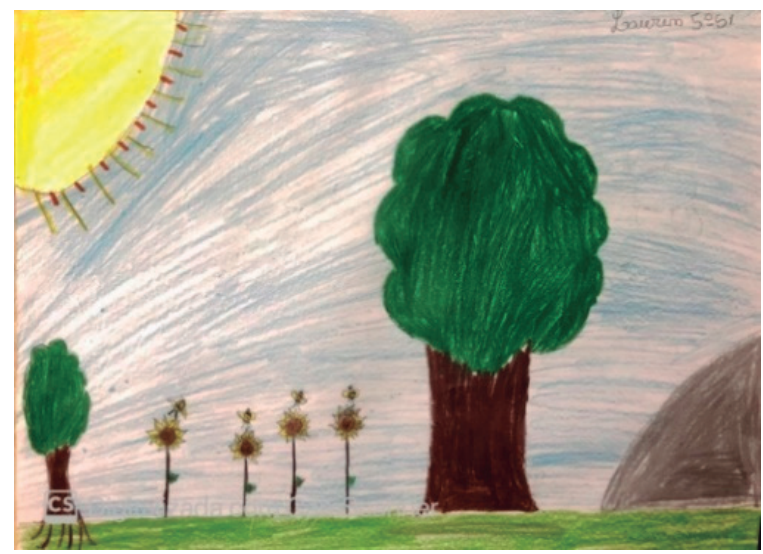

Fonte: acervo próprio.

Os resultados evidenciam a importância do ensino em ciências, a busca do estudante pelo saber, a reflexão, 0 aprendizado e ações que podem ser praticadas a fim de colaborar com a sustentabilidade, sendo possibilitada pelo professor. Goldschmidt et al. (2019) salientam a importância de proporcionar aos alunos de anos iniciais o conhecimento científico, com isso, a alfabetização cientifica pode ser construída em sala de aula partindo dos conhecimentos prévios dos alunos e incorporando sempre que necessário conhecimentos mais coerentes e adequados, os quais devem ser mediados pelo professor.

\section{CONSIDERAÇÕES FINAIS}

A importância das abelhas, da sustentabilidade e dos corredores ecológicos são temas emergentes dentro do ensino de ciências, sobretudo na área de ecologia. Além disso, tais temáticas tem uma forte ligação com o cotidiano das crianças e, cada vez mais, a mídia tem noticiado os prejuízos ambientais causados pela ação do homem ao meio ambiente.

Sendo assim, as concepções iniciais dos alunos voltados para as temáticas importância das abelhas e sustentabilidade se mostraram bastante adequadas para 0 nível escolar em que estão inseridos. No entanto quando questionados sobre os corredores ecológicos, a maioria dos alunos afirmou nunca ter ouvido falar do tema, sendo que estes constam de importantes alternativas para a manutenção da biodiversidade e, consequentemente, das abelhas nos ecossistemas. 
A partir desses entendimentos iniciais, criamos um grupo de estratégias que consistiram em momentos de diálogo, visitação à locais apícolas, construção de modelos didáticos de colmeias e abelhas, plantio de espécies melíferas e socialização dos novos saberes em uma mostra científica escolar. Por meio delas, houve uma ampliação dos saberes iniciais dos alunos. Assim, os conhecimentos relacionados às temáticas sustentabilidade e importância das abelhas foram enriquecidos com os novos conhecimentos relacionados aos corredores ecológicos, favorecendo para uma leitura de mundo mais ampla e comprometida com a manutenção da vida no planeta, permitindo assim uma aprendizagem significativa e um processo de alfabetização científica guiado pelos saberes iniciais das crianças.

Ao final deste trabalho esperamos contribuir para criação e/ou implementação de estratégias relacionadas às temáticas importância das abelhas, da sustentabilidade e dos corredores ecológicos em outros cenários educacionais e, assim, permitir uma educação científica pautada no respeito para com outros organismos e comprometimento com atitudes adequadas para a manutenção da vida no planeta.

\section{REFERÊNCIAS}

ABREU, I. D. S.; BUSSINGUER, E. C. D. A. Antropocentrismo, ecocentrismo e holismo: uma breve análise das escolas de pensamento ambiental. Derecho y Cambio Social. Peru, v. 10, n. 34, 2013. p. 1-11.

ALVES, J.M. Histórias em quadrinhos e educação infantil. Psicologia: Ciência e Profissão, v. 21, n. 3, 2001.

ALMEIDA, R. D. Do desenho ao mapa: iniciação cartográfica na escola. 2. ed. São Paulo: contexto, 2003.

ANJOS. L, F. R. 0 desaparecimento das abelhas: uma temática para 0 ensino de ciências. Tese (Mestrado em Ensino de Ciências) - Faculdade UnB Planaltina, Universidade de Brasília. Brasília, p. 46. 2020.

AUSUBEL, David. P. Aquisição e Retenção de Conhecimentos: Uma Perspectiva Cognitiva. Lisboa: Plátano, 2003.

BARBOSA, M. H. et al. Therapeutic properties of propolis for treatment of skin lesions. Acta Paulista de Enfermagem, v. 22, n. 3, p. 318-22,2009.

BARDIN, L. Análise de conteúdo. São Paulo: Edições 70, 2011.

BOER, N. 0 meio ambiente na percepção de alunos que recebem educação ambiental na escola. Ciência e Ambiente, Porto Alegre, v. 1, n. 8, p. 91-101, 1994.

CAVALCANTI, C. Sustentabilidade da economia: paradigmas alternativos de realização econômica. In: (Org.). Desenvolvimento e natureza: estudos para uma sociedade sustentável. 2. ed. São Paulo: Cortez, 1998. p. 153-174.

CARON, M. F.R. Concepções prévias de estudantes do $1^{0}$ ano do Ensino Médio sobre Reciclagem. Disponível em: https://bit.ly/3CwlzOH. Acesso em: 17/08/2020.

CORBY, H. V. et al. Parasaccharibacter apium, gen. nov. , sp. nov. , improves honey bee (Hymenoptera: Apidae) resistance to Nosema. Journal of economic entomology, v. 109, n. 2, p. 537-543, 2016.

CHASSOT, A. Alfabetização científica: uma possibilidade para a inclusão social. Revista Brasileira de Educação. Rio de janeiro, n. 22, p. 89-100, Jan. /Abr. 2003. Disponível em: https://bit.ly/3EHMGJo. Acesso em: 28 de fev. 2021. 
DIAMOND, J. M. The island dilema: lessons of morden biogeography studies for the design of natural reserves. Biological Conservation, v. 7, p. 129-146, 1975.

FAO. Conservation and management of pollinators for sustainable agriculture - the international response. FAO. Montreal, 2018. p. 1-18.

FREITAS, D. G.F. et al. Nível tecnológico e rentabilidade de produção de mel de abelha (Apis mellifera) no Ceará. Revista de Economia e Sociologia Rural, v. 42, p. 171-188, 2004.

FUNDO MUNDIAL PARA A NATUREZA. Em 2019, Terra entra no cheque especial a partir de 29 de julho. 2019. Disponível em: https://bit.ly/2Z9BJje. Acesso em: 01 set. 2021.

GARIBALDI, L. A. et al. Stability of pollination services decreases with isolation from natural areas despite honey bee visits. Ecology Letters, v. 14, p. 1062-1072, 2011.

GIL, A. C. Como elaborar projetos de pesquisa. 4. ed. São Paulo: Atlas, 2008.

GODIN, B. e GINGRAS, Y. What is scientific and technological culture and how is it measured? A multidimensional model. Public Understanding of Science, London, 9: 43-58, 2000.

GODOY, C.E.C. et al. A aprendizagem baseada em problemas e a introdução de conceitos químicos nas aulas de ciências no ensino fundamental II. In: XIV Encontro Nacional de Ensino de Química, 2008, Curitiba. Anais... Curitiba: UFPR, 2008.

GOLDSCHMIDT. A. I. et al. Classificação de seres vivos por alunos de anos iniciais do ensino fundamental: uma proposta de desenvolvimento de habilidades científicas. Revista Actio Docência. Curitiba. v. 4, n. 3, p. 110-130, set./dez. 2019.

GUIMARÃES, M. A dimensão ambiental na educação. São Paulo: Papirus, 1995.

GUIMARÃES, E. M.; FERREIRA L. B. M. 0 uso de modelos na formação de professores de Ciências. $2^{\circ}$ ENCONTRO REGIONAL SUL DE ENSINO DE BIOLOGIA, 3a JORNADA DE LICENCIATURA EM CIÊNCIAS BIOLÓGICAS DA UFSC. Anais... Florianópolis, 2 a 4 de novembro de 2006.

GUISSO, F. L.; e BAIÔCO, M. R. V. A educação ambiental e o papel do educador na cultura da sustentabilidade. Disponível em: https://bit.ly/2XErVh1. Acesso em: 11 set. 2020.

JACOBI, P. Educação ambiental, cidadania e sustentabilidade. Cadernos de pesquisa, v. 118, n. 3, p. 189-205, 2003.

JONES, P. et al. Sustaintability education: perspectives and practice across higher education. London: Earthscan, 2010.

KERR, W. E.; AMARAL, E. Flora apícola. In: Apicultura científica e prática. São Paulo: Secretaria da Apicultura do Estado de São Paulo, 1960. p. 47-59.

KERR, W. E. Abelhas indígenas brasileiras (Meliponíneos) na polinização e na produção de mel, pólen, geoprópolis e cera. Informe Agropecuário, n 13, p 15-22. 1987.

KERR, W. E. et al. Aspectos pouco mencionados da biodiversidade amazônica. Parcerias Estratégicas, Brasília, DF, n. 12, p. 20-41, set. 2001. 
LOPES, M.; FERREIRA. J. B.; SANTOS. E G. DOS. Abelhas sem-ferrão: a biodiversidade invisível. Agriculturas. v. 2, n. 4, dez. 2005.

LORENZETTI, L.; DELIZOICOV, D. Alfabetização científica no contexto das séries inicias. Ensaio - Pesquisa em Educação em Ciências, Belo Horizonte, v. 3, n. 1, jun. 2001.

MAIA, G. N. Caatinga: árvores e arbustos e suas utilizadas. 1 ed. São Paulo: D\&Z Computação Gráfica e Editora. 2004. p. 413.

MEFFE, G. K.; CARROLL, C. R. Principles of Conservation Biology. Sinauer Associates, 1997. 600 p.

MELO. N, F. P. ; BRENNAND, J. M. Empresas socialmente sustentáveis: o novo desafio da gestão moderna. Rio de Janeiro: Qualitymark, 2004.

MICHAELIS. Moderno Dicionário da Língua Portuguesa. Disponível em: https://bit.ly/3zoeEWw. Acesso em: 15 ago. 2020.

MORTIMER, E. F.; SCOTT, P. Atividade discursiva nas salas de aula: uma ferramenta sociocultural para analisar e planejar 0 ensino. Investigações em Ensino de Ciências. v. 7, n. 3. p. 283-306, 2002.

PEREIRA, M. L. O., BURITY, C. H. F. A Importância de Atividades Educativas Fora do Espaço Formal da Sala de Aula Para Ensino de Ciências. Saúde \& Ambiente em Revista, v. 6, n. 2, p. 16, 2011.

PETTIS, J. S. et al. Crop pollination exposes honey bees to pesticides which alters their susceptibility to the gut pathogen Nosema ceranae. PloS one, v. 8, n. 7, e70182, 2013.

RICKETTS, T. H., et al. Landscape Effects on Crop Pollination Services: are there general patterns? Ecology Letters. v. 11, p. 499-515, 2008.

ROSA, J. M. et al. Polinizadores em perigo: por que nossas abelhas estão Desaparecendo? In: Simpósio Internacional De Ciência, Saúde E Território, 6. 2017. Lages, Anais [...]. Santa Catarina: UDESC, 2017.

SILVA, A. W. P. et al. Crianças do hoje, genitoras do amanhã: Concepções de sustentabilidade de alunos do ensino fundamental. 2018. Dissertação (Programa de Pós-Graduação em Administração) - Centro de Ciências Sociais e Aplicadas, UFPB, João Pessoa - PB.

SILVA, D. M., et al. Saberes docentes e ensino de ecologia: uma investigação sobre a formação do pedagogo para 0 ensino de ciências. Revista Tecné, Episteme y Didaxis: TED. Año 2014, Número Extraordinario. ISSN Impreso: 01213814, ISSN web: 2323-0126 Memorias, Sexto Congreso Internacional sobre Formación de Profesores de Ciencias. Bogotá 08 al 10 de octubre de 2014.

SNUC - Sistema Nacional de Unidades de Conservação: texto da Lei 9.985 de 18 de julho de 2000 e vetos da presidência da República ao PL aprovado pelo Congresso Nacional. - São Paulo: Conselho Nacional da Reserva da Biosfera da Mata Atlântica, 2000. 2. ed. ampl. 76 p.

SODHI, N. S., et al. Bird use linear areas of a tropical city: implications for park connector design and management. Landscape and Urban Planning, v. 45, n. 2-3, 1999, p. 123 - 130. 
SOUZA, L., et al. As abelhas como agentes polinizadores (The bees agentes pollinizer's) REDVET. Revista Electrónica de Veterinária, v. 8, n. 3, p. 03, mar., 2007.

SOUSA, M. Sustentabilidade com a Turma da Mônica. São Paulo: Panini, 2012.

SOUZA, T. T. 0 Letramento Científico e Práticas dos Professores de Biologia do Ensino Médio. 2015. 137f. Dissertação (Mestrado Profissional em Ensino de Ciências Exatas) - Centro Universitário Univates, Lajeado-RS, 2015.

SUBRAMANIAM, M. A. Garden-based learning in basic education: a historical review. Monograph University of California, 2002. p. 1-12.

WRATTEN, S. D.; GILLESPIE, M.; DECOURTYE, A.; MADER, E.; DESNEUX, N. Pollinator habitat enhancement: Benefits to other ecosystem services. Agriculture, Ecosystems and Environment, Amsterdam, NL, v. 159, p. 112-122, 2012.

WILSON, E. 0.; WILLIS, E. 0. Applied biogeography. In. Ecological structure of species in communities. CODY, M. L.; DIAMOND, J. M. (eds.) Cambridge, Mass., Harvard University Press, p. 522-534, 1975.

RECEBIDO EM: 24 abr. 2021

CONCLUÍDO EM: 01 set. 2021 